\title{
Enhancing Undergraduate Education in Control Engineering
}

\author{
Arturo Rojas-Moreno, Ph.D. \\ Universidad de Ingenieria y Tecnologia - UTEC, Peru, arojas@utec.edu.pe
}

\begin{abstract}
This paper discusses the content of two basic courses in control engineering: Feedback Control Systems and Process Control with their associated Lab (laboratory) sessions. Such undergraduate level courses are lectured at the Electronic and Mechatronic Engineering Department (EMED) of UTEC (Universidad de Ingenieria y Tecnologia, Peru). The Lab sessions are performed in the Control Systems as well as in the Process Automation Labs. The structured experiments with their rubrics are carried out by the students after covering the corresponding theory classes. This methodology permits students to bridge the gap between theory and practice by means of hands-on and open (reconfigurable and reprogrammable) plants. An open plant allows the renewal of experiments. On the other hand, UTEC employs a methodology to engage undergraduate students to perform research. Several papers published in indexed international conferences ware based on various experiments performed by the students in the Lab sessions.
\end{abstract}

Keywords- Lab session rubric, open plant, feedback control systems course, process control course, control systems Lab, process automation Lab, bridging the gap methodology, hands-on methodology.

\section{INTRODUCTION}

At UTEC, the electronic and mechatronic engineering career lasts ten semesters. One of the career minors offered is process automation. During the first three semesters students take transversal courses on mathematics, physics, chemistry, and computer science. From the third to the eight semesters, students acquire a deep knowledge of their careers by taken the career courses. In the ninth and ten semesters students are also allowed to take elective courses of their choice, even courses from other engineering departments. They also have to develop and defend a thesis work, which is like to a personal capstone or an end-of-career project.

Simultaneously, starting from the first semester students experiment active learning based on projects of four degrees of difficulty and participate in interdisciplinary activities to develop soft competences and personality via selected courses in humanity, art, social sciences, and English language (the native language of the students is Spanish).

With the purpose of awaking and improving the natural research soft skills of the undergraduate students, UTEC foments in all semesters the development of engineering projects to solve social and industrial needs. Via a basic course in engineering lectured in the first semester, students become familiar with all the engineering programs and research facilities of UTEC. In such a course, students are lectured how

Digital Object Identifier (DOI):

http://dx.doi.org/10.18687/LACCEI2019.1.1.38

ISBN: 978-0-9993443-6-1 ISSN: 2414-6390 to develop engineering projects using PBL (Project-Based Learning) and EDP (Engineering Design Process) methods. The engineering projects are of two types: projects to solve social needs and projects to introduce students in the research world.

Projects are generated in several ways. For instance, at the beginning of one semester professors are asked to propose projects using a format for each one according to the degree of difficulty. Those projects are called VL1, VL2, VL3, and VL4 (VL stands for Vivir la Ingenieria). Some projects may be also proposed by students and other entities internal or external to UTEC. Those projects need the approval of specialist professors. Every semester, students are invited to be part of work teams to carry out the proposed projects under the supervision of an advising professor. At the end of the semester, a project fair is organized to show some selected projects. Each project requires posters and videos for presentation.

In the Electronic and Mechatronic Engineering Department of UTEC, some finished projects become papers as follows. Using the structure of a conference paper and under the supervision of an advising professor, students are asked to write the first version of their papers in Spanish using a scientific text editor based on Latex, preferably. Then, they translate their papers to English. After an improvement and review process, the paper is submitted to an international indexed conference. If the paper is accepted, the authors are taught how to prepare the paper presentation and trained for personal presentation. In [1]-[4], the methodology used in UTEC to awake and improve the natural research and soft skills of undergraduate students, as well as other related topics, are covered in detail.

The process automation minor offers the following courses: Feedback Control Systems (6th semester), Process Control and Industrial Instrumentation (7th semester), Industrial Networks (8th semester), Monitoring and Supervision Systems (8th semester), and Industrial Control Systems (8th semester). Some elective courses for this minor are: Nonlinear Control, Intelligent Control, Robust Control, Hydraulic and Pneumatic Systems, Robotics. All courses have Lab sessions, which are carried out in the Control Systems as well as in the Process Automation Labs.

This work is organized as follows. Sections II and III describe the plants of the Control System and Process Automation Labs, respectively. Section IV proposes the structure of a Lab session. Section V discusses the content and the associated Lab sessions of the Feedback Control System

$17^{\text {th }}$ LACCEI International Multi-Conference for Engineering, Education, and Technology: "Industry, Innovation, And Infrastructure for Sustainable Cities and Communities”, 24-26 July 2019, Jamaica. 
course, while Section VI is about the content and the Lab sessions of the Process Control course. Section VII presents some concluding remarks of this work.

\section{THE CONTROL SYSTEMS LABORATORY}

Fig. 1 shows the Control System Lab at UTEC. All plants of this Lab possess hand-on characteristic because they can be manipulated actively. Such plants are open because those accept reconfigurations (to create new experiments) and reprogramming. The plants of the Control Systems Lab are briefly described below.

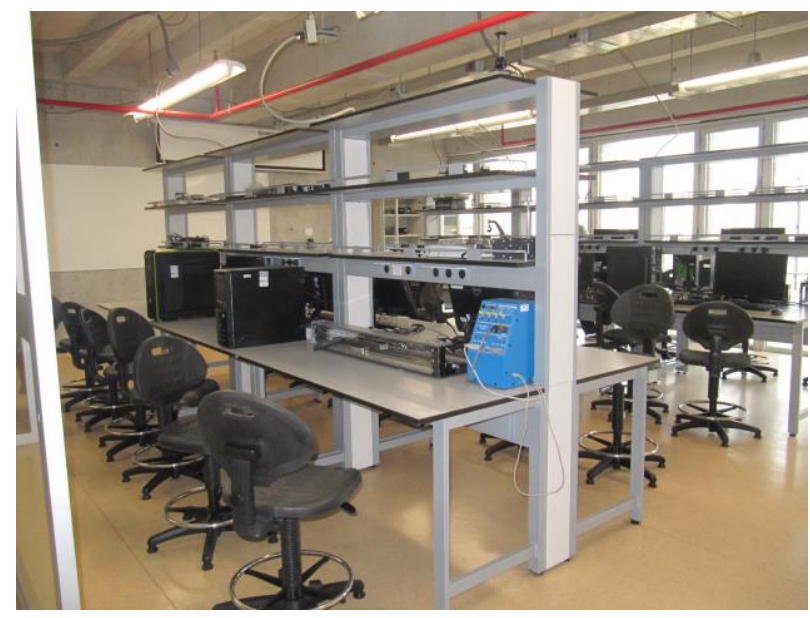

Fig. 1 The Control Systems Lab at UTEC.

The Magnetic Levitation plant (Maglev plant) implements closed loop levitation of either one or two magnetic disks located between two magnets using various control algorithms. This plant possesses laser feedback for position sensing. A Clike language is used to write real-time controller codes.

The industrial plant emulator (Emulator plant) permits to build many plant configurations containing linear (mass, dumper, spring) and nonlinear (backlash, Coulomb friction) elements. Speed and position feedback control system can be implemented with this plant, which employs a C-like language to write real-time controller codes.

With the Torsional plant, we can implement several practical plants of second, fourth, and sixth order like rigid bodies, flexibility in drives, and coupled vibrating systems. The control objective of such a plant is to control the angular position of a selected plant. The corresponding control algorithms are written in C-like code.

The rotary servo base plant (SRV02 plant) comprises a DC motor with an incremental encoder for angular position sensing, and an external gear train. The control objectives are to control the angular position and the speed of the motor shaft subject to linear and nonlinear loads. This plant employs control algorithms written in MATLAB/Simulink code.

The 2DOF (2 Degrees of Freedom) Planar Robot possesses four-links and five joints. The first and the last joints of this robot are attached to two SRV02 plants. An inverted pendulum or a gantry (non-inverted pendulum) can be attached to the central joint. The control algorithms are written in MATLAB/ Simulink code.

The Qube plant possesses a DC motor with reduction mechanism and incremental encoder. Linear and nonlinear loads can be articulated to the DC motor shaft. This plant permits to implement load speed and position control systems. A rotary inverted pendulum can be attached to the DC motor shaft which allows to control the angular position of the support arm and to keep the upright position of the pendulum. All control algorithms are written in MATLAB/Simulink code.

Position and speed feedback control systems can be implemented with the QNET DC motor control trainer plant (DC motor plant). The control algorithms are written in Labview code.

A temperature feedback control system is implemented with the QNET HVAC (Heating, Ventilation and Air Conditioning) trainer plant (HVAC plant). The control algorithms are written in Labview code.

The 1DOF and 2DOF Torsion plants possess a SRV02 plant attached to one or two sets comprising a flexible coupling with a rotational load. The control objectives are to control the angular positions of such loads. The control algorithms are written in MATLAB/Simulink language.

The control objective of the Laser Beam Stabilization plant (Laser plant) is to keep the nominal position of a low-power stationary laser beam source pointing at a single-axis in order to reduce oscillations less than 50 micrometer. A highresolution PSD (Position Sensing Detector) is used to pick up the reflected beam. The control algorithms are written in MATLAB/Simulink code.

The control objective of the 2DOF ball balancer plant (Balancer plant) is to keep a ball free to move on a plate that can swivel in any direction. Two SRV02 plants are attached to the sides of the plate using 2DOF gimbals. A digital camera mounted overhead is employed to captures two-dimensional images of the plate in order to track in real time the ball coordinates. The MATLAB/Simulink language is employed to elaborate the control algorithms.

The HFLC (High Fidelity Linear Cart) plant comprises an aluminum cart driven by a 3-phase brushless DC motor. The cart slides along two guide rails. Various experiments can be implemented with the HFLC plant: position control of the cart, control of a single, double, and triple inverted pendula, control of a single, double, and triple pendula (cranes), swing up control of an inverted pendulum, control of two independent inverted pendula, and control of a SLFJ (Single Linear Flexible Joint). The control algorithms are elaborated using the MATLAB/Simulink language.

A module, called the Servo plant, containing a DC servo, a brushless DC servo, and an induction servo, each of them equipped with gear train and optical encoder. The control objectives are the implementation of speed and position

Digital Object Identifier: (to be inserted by LACCEI).

ISSN, ISBN: (to be inserted by LACCEI).

$17^{\text {th }}$ LACCEI International Multi-Conference for Engineering, Education, and Technology: "Industry, Innovation, And Infrastructure for Sustainable Cities and Communities”, 24-26 July 2019, Jamaica. 
control systems for each servo using different control algorithms written in LabVIEW code. This Servo module has been patented by UTEC [5]. The works published in [6-7] employ the induction motor of this module.

The QBOT2 plant located in the Mechatronics Lab of UTEC is an open-architecture autonomous ground robot built on a 2-wheel mobile platform, which is equipped with built-in sensors and a vision system. This plant is able to follow arbitrary ground trajectories employing control algorithms written in the MATLAB/Simulink language.

A Training Suitcase for Automatic Control (TSAC) shown in Fig. 2 having brush and brushless DC servos, a stepping servo, and a temperature process. The DC servos are equipped with gear train and optical encoder. The controller is a Siemens PLC (Programmable Logic Controller). Various speed, position, and temperature control systems can be implemented with the TSAC, which will be patented in the near future.

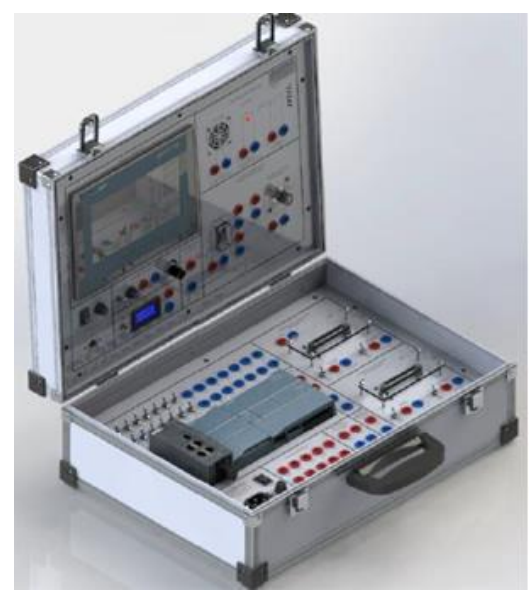

Fig. 1 The TSAC (Training Suitcase for Automatic Control).

\section{THE PROCESS AUTOMATION LABORATORY}

Fig. 2 depicts the Process Automation Lab of UTEC having three multipurpose plants and three monitoring \& supervision modules equipped with components as encountered in industry. Two monitoring \& supervision modules possess Rockwell Automation equipment while the other one has Siemens equipment. Such plants and the monitoring and supervision modules were designed by a team of professors of the Electronic and Mechatronic Engineering Department of UTEC, built in Lima-Peru, and patented [8-9]. The corresponding patents are pending. The Process Automation Lab is employed for the Process Control, Industrial Instrumentation, Industrial Networks, Monitoring and Supervision System, and Industrial Control System courses.

Fig. 3 depicts the P\&ID (Piping and Instrument Diagram) of the multipurpose plant, where T-10 is the water tank plant. Observe that flow rates $\mathrm{q}_{\mathrm{C}}$ (cold water) and $\mathrm{q}_{\mathrm{H}}$ (hot water) are entering into T-10. A warm water flow rate $\mathrm{q}_{\mathrm{D}}$ is exiting from $\mathrm{T}-10$. Such a tank possesses a drain pipe for emergency cases. The on-off valve DV-10 allows the passage of $\mathrm{q}_{\mathrm{C}}$. The control valve $\mathrm{FV}-10$ is used to regulate $\mathrm{q}_{\mathrm{C}}$, while the flow transmitter FT-10 measures it.

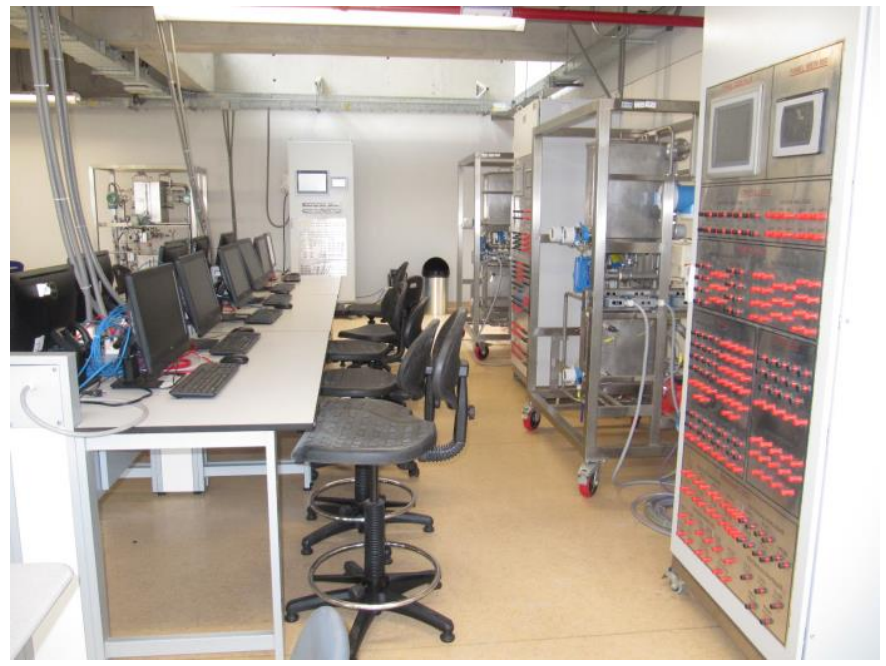

Fig. 2 The Process Automation Lab at UTEC showing in the foreground to the right a monitoring and supervision module, and then its corresponding multipurpose plant.

The flow rate $\mathrm{q}_{\mathrm{H}}$ (hot water) is regulated by the control valve FV-11 and measured by the flow transmitter FT-11. Inside the tank T-10 there is a temperature transmitter TT-10, and a pressure transmitter PT-10, which is used as a level transmitter. In the tank $\mathrm{T}-10$, there are an electric heating resistance and a power controller PW-10. The tank T-20 produces the required flow rate $\mathrm{q}_{\mathrm{H}}$ of hot water at a temperature of $50^{\circ} \mathrm{C}$. The flow rate $\mathrm{q}_{\mathrm{D}}$ of water exits $\mathrm{T}-10$ through the on-off valve DV-30.

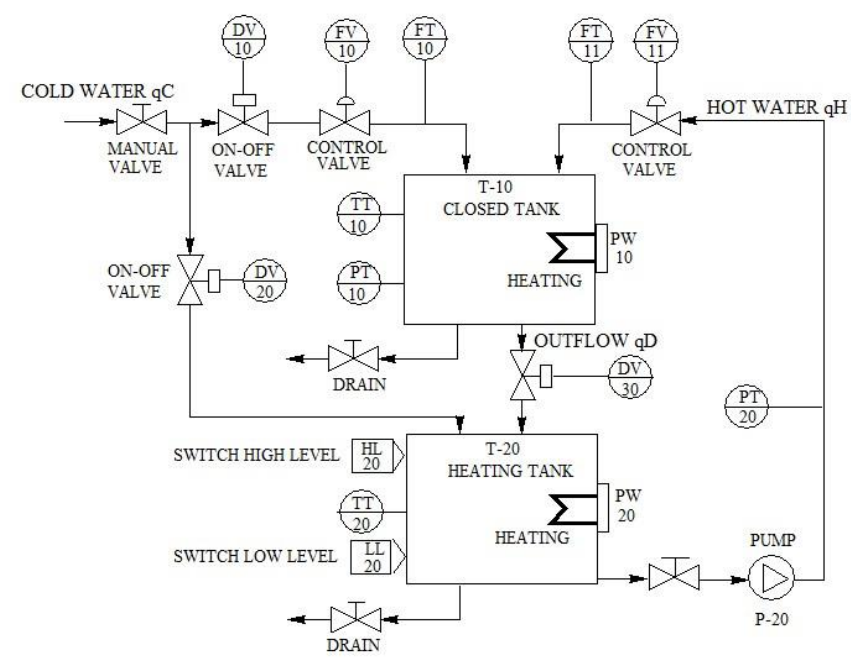

Fig. 3 P\&ID diagram of the multipurpose plant.

$17^{\text {th }}$ LACCEI International Multi-Conference for Engineering, Education, and Technology: "Industry, Innovation, And Infrastructure for Sustainable Cities and Communities", 24-26 July 2019, Jamaica. 


\section{STRUCTURED LABORATORY SESSIONS}

The theory of engineering courses at the Electronic and Mechatronic Engineering Department are lectured in two 2hour sessions per week, having the support of suitable Lab sessions to perform structured experiments to close the gap between theory and practice. From our point of view, a structured Lab session needs to fill the following requisites

- Seven 4-hour Lab sessions scheduled in a 16-week semester.

- Work teams of two members (occasionally three) during a Lab session.

- Reading material submitted to the students 1 or 2 weeks before the scheduled Lab session.

- An either entry or exit test based on the reading material for each Lab session.

- A Lab guide explaining clearly how to carry out the experiments of the Lab session.

- A personal evaluation rubric containing the goals to be achieved during the Lab session.

- A Lab report written at the end of a Lab session.

- Challenging questions to be solved during the scheduled date of the Lab session.

\section{THE FEEDBACK CONTROL SySTEMS COURSE}

The theory of the 5-credit Feedback Control Systems course is lectured during 15 weeks in a 16-week semester. Seven 4-hour Lab sessions are carried out during one semester. This course deals with SISO systems and covers the following topics in twelve chapters: system modeling in the Laplace and State-space domains, characteristics and stability analysis of open- and closed-loop systems, design of on-off and PID controllers, design of compensators using the root-locus and the frequency response methods, the design of state variable feedback (pole placement). The following software packets for simulation and real-time implementation are employed during the development of the course chapters: MATLABSimulink, C-like, and LabVIEW. The chapters and Lab sessions of such a course are described below.

Chapter 1: Introduction to feedback control systems, covering: discussion of various SISO (Single Input Single Output) and MIMO (Multiple Input Multiple Output) openand close-loop control systems in the continuous-time domain.

Chapter 2: Mathematical modeling of systems. Topics: dynamic modeling of systems using differential equations and the Laplace transform, the transfer function, block diagrams and signal-flow graph models, simulation of dynamic systems.

Chapter 3: Modeling in the state space domain. Covered topics: the state variables of a dynamic system, the state-space representation, the transfer function from the state-space model, the solution of the state-space model, the time response and the state transition matrix.
Chapter 4: Feedback Control Systems Characteristics. Contents: error signal analysis, control system sensitivity, disturbance signals, steady-state error, the cost of feedback.

Chapter 5: The performance of feedback control systems. Topics covered: test inputs signals, performance of secondorder systems, effects of a third pole, the steady-state error of systems, cost indices.

Chapter 6: On-off and PID (Proportional Integral Derivative) control. Contents: on-off control, P, PI, and PID control modes, structures of PID controllers, tuning rules of PID controllers, the wind up phenomena, discrete-time PID controllers.

Chapter 7: Pole placement design. This chapter covers: controllability and observability, P (Proportional) and PI (Proportional Integral) pole placement design, full observer design, pole placement design with full observer.

Chapter 8: The stability of linear feedback systems. Topics: the concept of stability, the Routh-Hurwitz criterion, the stability in the state-space domain.

Chapter 9: The root-locus method.Contents: the root-locus concept and procedure, parameter design via the root-locus method, negative gain root-locus.

Chapter 10: Frequency response methods. This Chapter covers the topics: frequency response plots and measurements, performance specifications in the frequency domain, Bode diagrams

Chapter 11: Stability in the frequency domain, covering: mapping contours in the s-plane, the Nyquist criterion, relative stability and the Nyquist criterion, system bandwidth, the stability of control systems with time-delays.

Chapter 12: The design of feedback control systems. Topics: approaches to system design, cascade compensation networks, phase-lead design using the Bode diagram, phaselead design using the root-locus, system design using integration networks, phase-lag design using the Bode diagram, phase-lag design using the root-locus, systems with a pre-filter.

The programmed Lab sessions for the 2019-1 semester are:

Lab 1: The TSAC.- With this Lab, students get familiar with an industrial PLC and its applications.

Lab 2: On-off position control of a brush DC servo using the TSAC and other plants of the Control Systems Lab. With this application, students learn to program and apply industrial software as encountered in the industry.

Lab 3: PID position control of a brush DC servo using the TSAC and all plants of the Control System Lab. The works published in [10-11] are based on the experiments employing the 1DOF Torsion plant, while the paper published in [12] uses the Maglev plant.

Lab 4: Temperature control using the TSAC and the QNET HVAC plant.

Lab 5: Pole-placement control (Control Systems Lab). This Lab session employs the Maglev, Emulator, SRV02,

$17^{\text {th }}$ LACCEI International Multi-Conference for Engineering, Education, and Technology: "Industry, Innovation, And Infrastructure for Sustainable Cities and Communities", 24-26 July 2019, Jamaica. 
Qube, 1 DOF-Torsion, and Laser plants of the Control System Lab.

Lab 6: Design of compensators using the root-locus (Control Systems Lab).- This Lab session employs the Torsional, Emulator, SRV02, Qube, 1 DOF Torsion, and Laser plants of the Control System Lab, as well as the QBOT2 plant of the Mechatronics Lab.

Lab 7: Design of compensators using the frequency response (Control Systems Lab). - This Lab session uses the same plants as the Lab session 6 .

\section{THE PROCESS CONTROL COURSE}

The theory of the 5-credit Process Control course is lectured during 15 weeks in a 16-week semester. Seven 4-hour Lab sessions are developed in one semester.

This course deals with the control of SISO and MIMO processes covering the following topics: discrete-time analysis, process control strategies, MIMO PID control, optimal LQR control, predictive control, fractional order control, control of time-delay processes. Such topics are covered in nine chapters:

Chapter 1: Discrete-time analysis. Topics covered: the $\mathrm{z}$ transform, the z-plane analysis, state-space analysis in the discrete-time domain, parameter estimation.

Chapter 2: Control strategies. Contents: P\&ID (Piping and Instrumentation Diagrams), cascade control, ratio control, feedforward control, override control, selective control, split-range control.

Chapter 3: MIMO PID control. Topics covered: centralized, decoupled, and decentralized MIMO controller design.

Chapter 4: Optimal LQR control of continuous-time processes. This Chapter deals with: optimal LQR control problem, steady-state optimal LQR control, Proportional (P) optimal LQR control, Proportional Integral (PI) optimal LQR control, full order observer design, $\mathrm{P}$ and PI optimal LQR control with full observer.

Chapter 5: Optimal LQR control of discrete-time processes. Contents: optimal LQR control problem, steadystate optimal LQR control, Proportional (P) optimal LQR control, Proportional Integral (PI) optimal LQR control, full order observer design, P and PI optimal LQR control with full observer.

Chapter 6: Predictive control. Topics covered: Model Base Predictive Control (MBPC) for SISO processes, MPPC for MIMO processes, Generalized Predictive Control (GPC) for SISO processes with a state-space model, GPC for MIMO processes with a state-space model.

Chapter 7: Fractional Order (FO) control of SISO processes covering: introduction, FO calculus, the Oustalup filter, the Muir approximation, from SISO IO (Integer Order) to SISO FO controllers.

Chapter 8: FO control of MIMO processes. Topics: from MIMO IO to MIMO FO controllers, applications. Some topics of this chapter are based on the work published in [13].
Chapter 9: Control of SISO and MIMO time-delay processes. Contents: PID control of SISO time-delay plants, MBPC control of SISO and MIMO stable time-delay plants, discrete-time LQR (Linear Quadratic Regulator) control of SISO and MIMO time-delay plants, LQ predictive control in the discrete state-space domain of SISO and MIMO stable, unstable, non- minimum phase and integral time-delay plants.

Seven 4-hour sessions in a 16-week semester are employed to perform the following experiments:

Lab 1: Process identification (Control Systems Lab). - All plants of the Control Systems Lab are used in this Lab session.

Lab 2: Rate control (Process Automation Lab).- This Lab session deals with the rate control of two flow rates of water employing the multipurpose plant and the monitoring and supervision module.

Lab 3: Cascade control (Process Automation Lab).- This Lab session implements a cascade control of the tank level using the flow rate of water using the multipurpose plant and the monitoring and supervision module.

Lab 4: Multiloop control of the water tank plant (Process Automation Lab).- In this Lab session, a multiloop control system is implemented using the multipurpose plant and the monitoring and supervision module to control the level and temperature of the water in a tank employing as control inputs the flow rate of cold water and the heat of an electric resistance. The works in [14-15] are based on experiments developed in this Lab session.

Lab 5: Optimal LQR control (Control Systems Lab). - All plants of the Control Systems Lab are used in this Lab session.

Lab 6: Predictive control (Control Systems Lab). - All plants of the Control Systems Lab are used in this Lab session.

Lab 7: Fractional order control (Control Systems Lab). All plants of the Control Systems Lab are used in this Lab session. The works published in [16-20] are based on the experiments performed with the Torsional, Maglev, Qube (servomotor), QBOT2, and Qube (inverted pendulum) plants, respectively.

\section{CONCLUDING REMARKS}

To enhance undergraduate education in control engineering, the Electronic and Mechatronic Engineering Department (EMED) of UTEC offer two basic 5-credit courses: Feedback Control Systems and Process Control which are lectured in two 4-hour sessions per week during 15 weeks in a 16-week semester. Students take four written test scheduled during the first 15 weeks, and a final exam programmed in the sixteenth week. Seven 4-hour Lab sessions per semester are also scheduled. The grade of each course over a maximum of 20 points is obtained using the following formula:

Course grade $=0.4 \mathrm{WT}+0.4 \mathrm{LS}+0.2 \mathrm{FE}$

$17^{\text {th }}$ LACCEI International Multi-Conference for Engineering, Education, and Technology: "Industry, Innovation, And Infrastructure for Sustainable Cities and Communities", 24-26 July 2019, Jamaica. 
In the above equation, WT, LS, and FE stand for the average grade of the written tests, Lab sessions, and final exam, respectively.

To obtain the minor process automation EMED student need to take the Feedback Control Systems, Process Control, Industrial Instrumentation, Industrial Networks, Monitoring and Supervision Systems, and Industrial Control Systems. By own selection, students may take elective courses in control engineering.

The Feedback Control Systems course deals with the control of continuous-time SISO processes. The learning outcomes of this course are: model and simulate control systems in the Laplace and state-space domains, analyze the characteristics and stability of feedback control systems, design on-off and PID feedback control systems, design compensators using the root-locus and frequency response methods, design pole placement controllers with full observers programming real-time controller using the MATLAB /Simulink, LabVIEW, and C-like languages.

The seven structured Lab sessions with their rubric evaluations are developed in the Control Systems Lab in order to bridge the gap between the theory and the practice, employing for this hands-on and open plants.

The Process Control course is about the control of SISO and MIMO plants in the continuous- and discrete-time domains. The learning outcomes of this course are: analyze discrete-time feedback control systems, design multi-loop feedback control systems using various strategies, design of MIMO PID feedback control systems, design SISO and MIMO optimal LQR feedback control systems in the continuous- and discrete-time domains, design of SISO and MIMO predictive control systems in the discrete-time domain, design of SISO and MIMO fractional order control systems in the continuous- and discrete-time domains, design of SISO and MIMO control systems having multiple time-delays. The seven programmed Lab sessions with their rubric evaluations are carried out in the Process Automation Lab with purpose of bridging the gap between the theory and the practice, using for this hands-on and open plants.

Using the UTEC methodology to engage undergraduate students to perform research, undergraduate students were able to produce published papers in indexed international conference based on some of the experiments developed in the Lab sessions.

\section{REFERENCES}

[1] V. Murray and C. Matsuno, "Proceedings from research as a new learning outcomes in undergrad engineering programs," in IEEE 7th Intenational Conference on Engineering Education (ICEED), Kanazawa, Japan, Nov. 17-18, 2015, pp. 73-78.

[2] V. Murray and C. Matsuno, "Research laboratories and training undergraduate students from the freshman level to produce international conference-level publications," in International Conference on Interactive Collaborative Learning (ICL), Dubai, Dec. 03-06, 2014, pp. 553-560.

[3] V. Murray and C. Matsuno, "Research skills and conference papers as part of the undergraduate engineering programs," in IEEE 8th
International Conference on Engineering Education (ICEED), Langkawi, Malaysia, Dec. 7-8, 2015, pp. 96-101.B.

[4] A. Rojas-Moreno, "Undergrad Research in Control Engineering," in III IEEE World Engineering Education Conference, Lima, Peru, March 1720, 2019, pp. 1-4.

[5] A. Rojas-Moreno, "Embedded control system for electric servomotors", Peru Patent, Resolution 000-688-2016/DIN-INDECOPI, June 28, 2016.

[6] A. Rojas-Moreno, "Parameter Extraction of an Induction Motor with Gearbox for Dynamic Simulation," in IEEE Andean Council International Conference (ANDESCON), Oct. 19-21, 2016, Arequipa, Peru, pp. 1-4.

[7] A. Rojas-Moreno, "Determinacion experimental de los parametros del circuito equivalente de un motor de inducción trifasico con caja de reduccion", I + i (Investigacion Aplicada e Innovacion), vol. 11, pp. 3641, Nov 23, 2017.

[8] A. Rojas-Moreno, Victor Murray, and Roberto Castillo,"A multipurpose industrial module for control and supervision", Peru Patent, Resolution № 001-035-2019/DIN-INDECOPI, March 28, 2019.

[9] A. Rojas-Moreno, Victor Murray, and Roberto Castillo, "A multipurpose industrial plant for control and instrumentation", Peru Patent, Resolution in progress-INDECOPI, June, 2019.

[10] A. Rojas-Moreno et al., "Control of the Angular Position of a Rotary Torsion Plant Using a 2DOF FO PID Controller," IEEE XXXVIII Convencion de Centro America y Panama, CONCAPAN, El Salvador, Nov. 7-9, 2018, pp. 1-4.

[11] A. Rojas-Moreno et al., "2DOF PID Control of the Angular Position of a Rotary Torsion Plant", in IEEE XXV International Conference on Electronics, Electrical Engineering and Computing (INTERCON), Lima, Peru, Aug. 15-18, 2018, pp. 1-4.

[12] A. Rojas-Moreno et al., "2DOF PID Control of the Angular Position of a Rotary Torsion Plant", in IEEE XXV International Conference on Electronics, Electrical Engineering and Computing (INTERCON), Lima, Peru, Aug. 15-18, 2018, pp. 1-4.

[13] A. Rojas-Moreno and C. Cuevas-Condor, "PD and PID Control of a Magnetic Levitation System - An Experimental Comparative Study", in IEEE XXIV International Conference on Electronics, Electrical Engineering and Computing (INTERCON), Cusco, Peru, Aug. 15-18, 2017, pp. $1-4$

[14] A. Rojas-Moreno et al.,, "FO Based-LQR Stabilization of the Rotary Inverted Pendulum," in lemph\{The IEEE 28th Chinese Control and Decision Conference (CCDC) \}, Yinchuan, China, May 28-30, 2016, pp. $4292-4297$.

[15] A. Rojas-Moreno and G. J. Hernandez-Garagatti, "Modeling of a Multipurpose Water Tank Plant", in IEEE XXIV International Conference on Electronics, Electrical Engineering and Computing (INTERCON), Cusco, Peru, Aug. 15-18, 2017, pp. 1-4.

[16] A. Rojas-Moreno, "An Approach to Control MIMO Time-Delay Processes," Global and Stochastic Analysis (GSA)\}, vol. 4, no. 2, Sep. 2017, Available at: http://www.mukpublications.com/gsavol4no2.php

[17] A. Rojas-Moreno and G. Perez-Valenzuela, "Control of a Torsional Plant Using IO and FO Compensators", in IEEE XXIV International Conference on Electronics, Electrical Engineering and Computing (INTERCON), Cusco, Peru, Aug. 15-18, 2017, pp. 1-4.

[18] A. Rojas-Moreno and C. Cuevas-Condor, "FO Control of a Magnetic Levitation System," in Electronic Congress (E-CON UNI), Lima, Peru, Nov. 22--24, 2017, pp. 1--4.

[19] A. Rojas--Moreno, "Real--Time Tracking Control of a Position Servo Employing Fractional Order Controllers," in Electronic Congress (ECON UNI), Lima, Peru, Nov. 22-24, 2017, pp. 1-4.

[20] A. Rojas-Moreno and G. Perez-Valenzuela, "Fractional Order Tracking Control of a Wheeled Mobile Robot", in IEEE XXIV International Conference on Electronics, Electrical Engineering and Computing (INTERCON), Cusco, Peru, Aug. 15-18, 2017, pp. 1-4.

[21] A. Rojas-Moreno and G. J. Hernandez-Garagatti, "MIMO Fractional Order Control of a Multipurpose Water Tank Plant", presented at IEEE Transaction of Control Systems Technology, 2019.

$17^{\text {th }}$ LACCEI International Multi-Conference for Engineering, Education, and Technology: "Industry, Innovation, And Infrastructure for Sustainable Cities and Communities", 24-26 July 2019, Jamaica. 